\section{$\underset{\substack{\text { hommes } \\ \text { \& migrations }}}{ }$}

\section{Hommes \& migrations}

Revue française de référence sur les dynamiques

migratoires

1286-1287 | 2010

Les migrations subsahariennes

\title{
Jean-François Bayart, Les Études postcoloniales, un carnaval académique
}

Paris, Karthala, 2010, 126 pages, 15 euros

\section{Mustapha Harzoune}

\section{(2) OpenEdition}

1 Journals

Édition électronique

URL : http://journals.openedition.org/hommesmigrations/1701

DOI : 10.4000/hommesmigrations. 1701

ISSN : 2262-3353

Éditeur

Musée national de l'histoire de l'immigration

Édition imprimée

Date de publication : 1 juillet 2010

Pagination : 306-307

ISSN : 1142-852X

Référence électronique

Mustapha Harzoune, "Jean-François Bayart, Les Études postcoloniales, un carnaval académique ", Hommes \& migrations [En ligne], 1286-1287 | 2010, mis en ligne le 29 mai 2013, consulté le 22 septembre 2020. URL : http://journals.openedition.org/hommesmigrations/1701 ; DOI : https:// doi.org/10.4000/hommesmigrations.1701

Ce document a été généré automatiquement le 22 septembre 2020.

Tous droits réservés 


\title{
Jean-François Bayart, Les Études postcoloniales, un carnaval académique
}

\author{
Paris, Karthala, 2010, 126 pages, 15 euros
}

Mustapha Harzoune

\section{RÉFÉRENCE}

Jean-François Bayart, Les Études postcoloniales, un carnaval académique, Paris, Karthala, 2010, 126 pages, 15 euros

1 Directeur de recherche au CNRS, auteur de L'État en Afrique (Fayard, 1979), de L'Illusion identitaire (Fayard, 1996), de La Politique du ventre (Fayard, 2006) et, plus récemment de L'Islam républicain. Ankara, Téhéran, Dakar (Albin Michel, 2010), Jean-François Bayart se livre ici à une descente (argumentée) en flèche, une critique tous azimuts des études postcoloniales en France. Ce courant en vogue dans l'Hexagone depuis les années quatre-vingt-dix voit "dans la 'situation coloniale' et dans sa reproduction l'origine et la cause des rapports sociaux contemporains, qu'ils soient de classe, de genre ou d'appartenance communautaire, tant dans les anciennes colonies que dans les anciennes métropoles" selon la définition de l'auteur.

2 Après en avoir dégagé la filiation anglo-saxonne et rappelé les conditions sociales et politiques (la globalisation et les migrations internationales) de son émergence, JeanFrançois Bayart en montre la diversité, l'extrême "hétérogénéité". Au détour de deux pages, il reconnaît aux études postcoloniales au moins deux intérêts : celui de ne pas se dessaisir du fait colonial et, reprenant une formule, celui de "sauver l'Histoire de la nation ", autrement dit permettre de décentrer le regard sur l'histoire nationale. Un intérêt très vite relativisé par le fait que ces thèmes, et d'autres encore, sont déjà présents chez bien des auteurs qui ont su, eux, éviter certains "pièges" dans lesquels seraient tombés les maîtres ès études postcoloniales.

3 Jean-François Bayart s'amuse des postures de dénonciation et/ou de victimisation adoptées par les apôtres des études postcoloniales. À ce propos, s'appuyant sur nombre 
d'exemples, il démontre que la France ne s'est nullement détournée de son histoire coloniale et encore moins des expressions nouvelles (musique, cinéma, littérature...) nées d'une sensibilité postcoloniale. Il multiplie les références indiquant, malgré ce que disent les avocats des études postcoloniales, que les universités n'ont pas snobé les travaux sur la période coloniale et ses retombées. Il montre aussi ce que lesdites études postcoloniales doivent aux travaux des Foucault, Sartre, Fanon et autres Bourdieu. Pire, pour Jean-François Bayart, ces études "sont contestables et conduisent l'étude du fait colonial ou postcolonial dans des impasses, au risque d'une vraie régression scientifique par rapport aux acquis de ces trente dernières années". Ces dénonciations, faciles et impératives, cacheraient mal, toujours selon l'auteur, la recherche d'une "rente d'éminence", la mise en place d'une "stratégie de niche" par les promoteurs desdites études.

4 Au centre de sa critique, Jean-François Bayart dénonce les dérives culturalistes des études postcoloniales: le primat de la problématique culturaliste sur toute autre considération dans la lutte contre les inégalités sociales ; le primat accordé à l'étude des "discours" et des "representations", négligeant ainsi l'études des "pratiques". Le résultat conduit les études postcoloniales à s'enfermer dans "le concept catastrophique d"identité" et à réifier la condition postcoloniale. Tout cela se traduit, en France du moins, par une ethnicisation de la question sociale et politique des banlieues et à privilégier la question du racisme sur, par exemple, la vieille notion de lutte de classes.

5 Jean-François Bayart attribue ces "derives" à une double "dé-historisation": du fait colonial d'abord, du passage - des continuités ou discontinuités - du moment colonial à la situation postcoloniale, ensuite. Ce que l'auteur nomme d'une formule savante la “ concaténation du moment colonial au moment postcolonial". Autrement dit, la "reproduction mécanique, univoque et surdéterminante du colonial". Mais voilà, pour l'auteur, les études postcoloniales ne disent rien "par le truchement de l"histoire effective' [...], des conditions de l'éventuelle transmission de cet heritage". Cette mystérieuse "concatenation" a au moins le mérite de ravir quelques "Indigènes de la République", tout heureux de s'affubler de ce qu'ils croient être le masque de leurs aînés et de participer au défoulement de ce " carnaval académique" ici dénoncé et où sont reproduites, singées, les situations de dominations coloniales et "en particulier [les] catégories identitaires nées de celles-ci". Plus grave peut-être, en matière de recherches et de réflexion, les études postcoloniales appauvriraient la pensée en refusant, par exemple, de replacer l'étude de l'empire colonial dans la catégorie générique des empires; en se détournant de l'étude du passage de l'empire à l'État-Nation ; en négligeant l'autonomie du social par rapport au politique ou en sous-estimant "l'historicité propre" des sociétés africaines et asiatiques, et ce malgré la domination coloniale ou plutôt les dominations coloniales - car la diversité des situations, des durées, ici aussi, importent. "Le fait colonial" est pluriel.

Citant de nombreuses études et recherches pluridisciplinaires, françaises mais aussi étrangères, s'appuyant sur une imposante bibliographie (pas moins de vingt-cinq pages), Jean-François Bayart invite le lecteur à prendre en considération la formidable (et stimulante) complexification du regard posé sur ces questions par les travaux menés "dans la discrétion de l'université et des laboratoires de recherché". 